\title{
Cross-sectional association between diet quality and cardiometabolic risk by education level in Mexican adults
}

\author{
Nancy López-Olmedo, Barry M Popkin, Penny Gordon-Larsen and Lindsey Smith Taillie* \\ Department of Nutrition, Gillings School of Public Health, University of North Carolina, 123 West Franklin Street, CB \# \\ 8120 Carolina Square, Chapel Hill, NC 27516-3997, USA
}

Submitted 14 August 2018: Final revision received 12 March 2019: Accepted 5 April 2019: First published online 8 July 2019

\begin{abstract}
Objective: Understanding the association between diet quality and cardiometabolic risk by education level is important for preventing increased cardiometabolic risk in the Mexican population, especially considering pre-existing disparities in diet quality. The present study examined the cross-sectional association of overall diet quality with cardiometabolic risk, overall and by education level, among Mexican men and women.

Design: Cardiometabolic risk was defined by using biomarkers and diet quality by the Mexican Diet Quality Index. We computed sex-specific multivariable logistic regression models.

Setting: Mexico.

Participants: Mexican men ( $n$ 634) and women ( $n$ 875) participating in the Mexican National Health and Nutrition Survey 2012.

Results: We did not find associations of diet quality with cardiometabolic risk factors in the total sample or in men by education level. However, we observed that for each 10-unit increase in the dietary quality score, the odds of diabetes risk in women with no reading/writing skills was 0.47 (95\% CI $0.26,0.85)$ relative to the odds in women with $\geq 10$ years of school (referent). Similarly, for each 10-unit increase of the dietary quality score, the odds of having three $v$. no lipid biomarker level beyond the risk threshold in lower-educated women was 0.27 (95\% CI 0.12, $0.63)$ relative to the odds in higher-educated women.

Conclusions: Diet quality has a stronger protective association with some cardiometabolic disease risk factors for lower- than higher-educated Mexican women, but no association with cardiometabolic disease risk factors among men. Future research will be needed to understand what diet factors could be influencing the cardiometabolic disease risk disparities in this population.
\end{abstract}

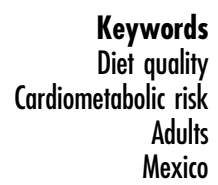

Cardiometabolic diseases are a major public health concern in Mexico. In 2013, diabetes and IHD were ranked as top causes of morbidity and mortality in $\mathrm{Mexico}^{(1)}$. Diets high in energy, saturated fat, sodium, refined cereals or added sugar, and low in fruits, vegetables or wholegrain products, were within the top risk factors that accounted for the most disease in the country ${ }^{(1)}$. However, the focus on analysing single nutrients or foods may not provide a realistic picture of the association between diet and health outcomes, since the combinations and quantities of foods and beverages consumed can have synergistic or antagonistic effects ${ }^{(2)}$.

To address this concern, many studies have analysed the role of overall diet quality in association with non-communicable diseases, including cardiometabolic diseases, using index-based dietary patterns that capture the complexity of the $\operatorname{diet}^{(3-5)}$. Results of randomized controlled trials show that improving diet quality can reduce the risk of cardiometabolic diseases, including type 2 diabetes and $\mathrm{CVD}^{(6-8)}$. Some studies have also found that diet quality indices are associated with concentrations of different biomarkers, which themselves are strong predictors of cardiometabolic diseases. Specifically, better diet quality has been associated with lower levels of C-reactive protein and higher levels of HDL-cholesterol ${ }^{(9,10)}$, which are associated with cardiovascular risk ${ }^{(11,12)}$. However, the association of overall diet quality with other biomarkers of cardiometabolic risk, including diabetes, atherogenic dyslipidaemia and chronic inflammation, has been scarcely studied, which is relevant 
given the burden of these conditions in the Mexican population $^{(1)}$. Furthermore, there is little understanding of whether the relationship between diet quality and cardiometabolic biomarkers varies by sex, despite previous evidence that women have more cardiometabolic risk than men because of inherent and lifestyle factors ${ }^{(13,14)}$.

Even less is known about whether the association between diet quality and cardiometabolic biomarkers varies by socio-economic status (SES). This is relevant in countries like Mexico where there are pre-existing disparities in dietary intakes by SES. For example, in 2012, the intakes of fruits, vegetables, saturated fats and added sugars were higher among Mexicans with high compared with low SES ${ }^{(15,16)}$. In addition, the consumption of corn and corn-based foods and beans was associated with lower SES among Mexican adults ${ }^{(17)}$. A household-based assets index is typically used in Mexican national surveys as proxy of SES, especially as a proxy of income. Even though the assets index is a rapid and simple method for collecting SES data, it also has the main limitation that its interpretation may depend on the relationship of the individual to the household ${ }^{(18)}$. On the other hand, education level garners a high response rate and is measured at individual level, unlike other indicators of SES ${ }^{(19)}$. Moreover, education level has been associated with more financial resources, better social-psychological profiles and healthier lifestyles (e.g. less smoking, more physical activity, better dietary patterns), and these may have synergistic effects ${ }^{(20,21)}$. We would expect to find a stronger inverse association between diet and cardiometabolic risk among higher- compared with lower-educated groups, since better diet among the more highly educated might interact with other favourable health factors to produce larger improvements in cardiometabolic risk. An understanding of whether education modifies the association between diet quality and cardiometabolic risk will be important for developing food policies to prevent increased cardiometabolic risk in Mexicans considering the potential differences by sex and education.

We aimed to determine whether higher overall diet quality was associated with lower cardiometabolic risk in Mexican adults by sex. Furthermore, we examined whether the association between overall diet quality and cardiometabolic risk was different across education levels.

\section{Participants and methods}

\section{Study design and population}

The National Health and Nutrition Survey (ENSANUT; from its Spanish name Encuesta Nacional de Salud y Nutrición) is a probabilistic survey with health and sociodemographic information obtained from 96031 individuals from 50528 randomly selected households. Fasting blood samples and dietary intake data were obtained from a sub-sample of participants.
We included non-pregnant and non-lactating adults aged 20-69 years with information on dietary intake and fasting blood samples ( $n$ 1921). We excluded individuals who did not remember or answer if they were affiliated in a health insurance plan ( $n 3$ ), with previous diagnosis of diabetes or hypertension ( $n$ 387) and with potential implausible energy intakes, that is with a ratio of total energy intake to estimated energy requirement (in logarithmic scale) below -3 SD and above +3 SD ( $n$ 30), as previously described ${ }^{(15)}$. A total of 324 individuals were excluded for one variable and eighty-eight for two or more variables; therefore, the analytic sample was composed of 1509 adults (58\% women).

\section{Study measurements}

\section{Cardiometabolic biomarkers}

Two fasting blood samples, whole blood and serum samples, were obtained from an antecubital vein for each participant. Serum was separated by spinning down the blood sample in situ at $2500 \mathrm{~g}$ in a portable centrifuge. Serum and whole blood aliquots were stored in cryovials placed in liquid nitrogen and transported to the National Institute of Public Health in Cuernavaca, Mexico. The serum concentrations of glucose, TAG, total cholesterol and HDL-cholesterol were measured in an automatic immunoassay analyser (CI8200 Architect; Abbott Diagnostics, Wiesbaden, Germany). Glucose was measured using glucose oxidase, TAG using a hydrolysis method, total cholesterol using an enzymatic digestion and oxidation method, and HDL-cholesterol by a direct enzymatic colorimetric method after removing chylomicrons. LDL-cholesterol was calculated using the Friedewald equation ${ }^{(22)}$. C-reactive protein was assessed by nephelometry, using monoclonal ultrasensitive antibodies (Behring Nephelometer 100 Analyzer; Behring Laboratories, Messer Grisheim GmbH, Frankfurt, Germany).

\section{Definitions of diabetes, atherogenic dyslipidaemia and inflammatory risk}

We used nationally and internationally accepted definitions of cardiometabolic risk. For diabetes risk, we used high fasting glucose $(\geq 100 \mathrm{mg} / \mathrm{dl})^{(23)}$. We considered the following lipid biomarkers: high TAG ( $>150 \mathrm{mg} / \mathrm{dl})$, low HDL-cholesterol ( $<40 \mathrm{mg} / \mathrm{dl}$ for men, $<50 \mathrm{mg} / \mathrm{dl}$ for women) and high LDL-cholesterol $(>130 \mathrm{mg} / \mathrm{dl})^{(23,24)}$, and defined atherogenic dyslipidaemia risk as none, one, two or all lipid biomarkers beyond the risk threshold. Inflammatory risk for CHD was represented by C-reactive protein $>3 \mathrm{mg} / \mathrm{l}$ but $<10 \mathrm{mg} / \mathrm{l}^{(25)}$.

\section{Dietary intake}

Details on dietary collection and assessment are described elsewhere; but in brief, dietary information was obtained from a random sub-sample of ENSANUT participants using the 24 h dietary recall developed by the US Department of 
Table 1 Mexican Diet Quality Index: components and criteria for scoring

\begin{tabular}{|c|c|c|c|}
\hline Food component & Maximum points & Criteria for minimum score $(0)$ & Criteria for maximum score \\
\hline \multicolumn{4}{|l|}{ Adequacy } \\
\hline Vegetables & 10 & 0 servings & $>3$ servings $/ 2000 \mathrm{kcal}$ \\
\hline Whole fruit & 10 & 0 servings & $\geq 3$ servings $/ 2000 \mathrm{kcal}$ \\
\hline \multicolumn{4}{|l|}{ Wholegrain cereals } \\
\hline Women & 5 & 0 servings & $\geq 3$ servings $/ 2000 \mathrm{kcal}$ \\
\hline \multicolumn{4}{|r|}{ 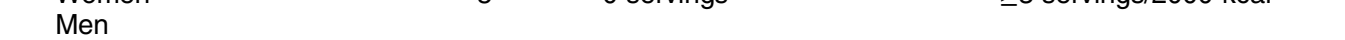 } \\
\hline Legumes & 10 & 0 servings & $\geq 2$ servings $/ 2000 \mathrm{kcal}$ \\
\hline Seafood, poultry or eggs & 5 & $<1$ serving/2000 kcal ${ }^{*}$ & $\geq 2$ servings $/ 2000 \mathrm{kcal}$ \\
\hline Low-fat dairy & 5 & 0 servings & $\geq 3.5$ servings $/ 2000 \mathrm{kcal}$ \\
\hline Polyunsaturated fat & 5 & $<6 \%$ of total energy intake & $>10 \%$ of total energy intake \\
\hline \multicolumn{4}{|l|}{ Moderation } \\
\hline $100 \%$ fruit juices & 5 & $>250 \mathrm{ml} / 2000 \mathrm{kcal}$ & $\leq 125 \mathrm{ml} / 2000 \mathrm{kcal}$ \\
\hline Refined grains & 5 & $>3$ servings $/ 2000 \mathrm{kcal}$ & $\leq 1$ serving $/ 2000 \mathrm{kcal}$ \\
\hline Red and processed meat & 5 & $>1.5$ servings $/ 2000 \mathrm{kcal}$ & $\leq 0.5$ serving $/ 2000 \mathrm{kcal}$ \\
\hline Added sugars & 15 & $>10 \%$ of total energy intake & $<5 \%$ of total energy intake \\
\hline Sodium & 15 & $>2 \mathrm{~g} / 2000 \mathrm{kcal}$ & $\leq 1.5 \mathrm{~g} / 2000 \mathrm{kcal}$ \\
\hline Saturated fat & 5 & $>10 \%$ of total energy intake & $<7 \%$ of total energy intake \\
\hline Total & 100 & 0 & 100 \\
\hline
\end{tabular}

*2000 kcal $=8372 \mathrm{~kJ}$.

Agriculture (automated five-step multiple-pass method), adapted to the Mexican context ${ }^{(26,27)}$. A second 24 h dietary recall was conducted in a random sub-sample of $9 \%$ of participants with the first $24 \mathrm{~h}$ dietary recall. We used information of the first $24 \mathrm{~h}$ recall only.

\section{Mexican Diet Quality Index}

We developed the Mexican Diet Quality Index (MxDQI) based on the Mexican Dietary Guidelines, which are focused on preventing overweight, obesity and other non-communicable diseases, promoting healthy eating habits, preserving the food culture and supporting sustainable food production ${ }^{(28)}$. We used the number of servings recommended for adults with a total energy intake requirement of $8372 \mathrm{~kJ} / \mathrm{d}$ (2000 kcal/d; see the online supplementary material, Supplemental Table S1 for more details) to create thirteen MxDQI components. The dietary components are shown in Table 1. Even though several components (e.g. whole fruit, whole- and refined-grain cereals, red and processed meat, sodium) for the MxDQI are similar to those reported in other dietary indices, such as the Healthy Eating Index, Alternate Healthy Eating Index, Dietary Approaches to Stop Hypertension score and the Mediterranean diet score, the MxDQI includes specifications based on the Mexican context. For instance, we included in the MxDQI a component related to $100 \%$ fruit juice given its relatively high consumption among Mexicans $^{(29)}$. Likewise, we used cut-off points recommended by the WHO, as well as recommendations on fat intake for the Mexican population, to define minimum and maximum scores for polyunsaturated fat, saturated fat and added sugars ${ }^{(30-32)}$. We defined scores between 0 (non-compliance) and 15 (intakes close to recommended) for each component. Specifically, we assigned a maximum score of 5 to those MxDQI components derived from the same food group (e.g. whole-grain and refined-grain cereals). We also assigned the added sugars and sodium components a maximum score of 15 , given their high consumption in the Mexican population and therefore their potential impact on health ${ }^{(33,34)}$.

\section{Statistical analysis}

We conducted all analyses in the statistical software package Stata version 15.0 (2017). We used survey commands to account for survey design and weighting to generate nationally representative results. Statistical tests were two-tailed and considered significant at $P<0.05$. We first descriptively examined characteristics of biomarkers and anthropometric measurements, total diet scores and sociodemographic variables by education level and sex. We performed sex-specific binary logistic regression models for testing the association of total diet quality score with diabetes and inflammatory risk. We analysed the association between total dietary quality score and atherogenic risk using sex-specific multinomial logistic regression models, using as reference the category of having no lipid biomarker beyond the risk threshold. We examined the associations between each 10-unit increase in total diet quality score and cardiometabolic risks. We adjusted the models for age (continuous, quadratic or categorical term, depending on the lowest Akaike information criterion value identified for each model), total energy intake, number of servings of alcohol, parity (none, $1-2,3-4$ and $\geq 5$ pregnancies), education level (no reading/writing skills; reading/ writing skills or 3-9 years of school; $\geq 10$ years of school), tertiles of asset index (low/medium/high) as a proxy of income, health insurance/coverage (social, linked to the formal labour market; popular, funded with general taxes; and uninsured), smoking status (current/former/none), region (North/Central/South) and area of residence (urban/rural). To test whether the associations differed by education level, we included models with interaction 
terms between total diet score and the three defined levels of education: (i) no reading/writing skills and (ii) reading/ writing skills or $3-9$ years of school $v$. (iii) $\geq 10$ years of school. We used as reference the category of $\geq 10$ years of school. We obtained the overall $P$ values for interaction through global Wald tests.

\section{Sensitivity analyses}

We did not include physical activity in the main analyses due to the poor validity of the International Physical Activity Questionnaire short form for assessing physical activity among Mexican adults ${ }^{(35)}$. However, physical activity could be an important confounder of the relationship between diet quality and cardiometabolic biomarkers. Thus, we conducted sensitivity analyses to test whether the inclusion of physical activity in models altered the associations between diet quality and cardiometabolic risk. We also conducted analyses in which corn tortillas were not considered as a wholegrain cereal, since it is uncertain whether all corn tortillas are made with whole grains.

\section{Results}

Sociodemographic, health and lifestyle characteristics of Mexican adults by sex and education level are shown in Table 2. A higher percentage of adults with no reading/ writing skills exceeded the threshold for diabetes risk in comparison with those with higher education. Likewise, a higher percentage of men with lower education were categorized with atherogenic dyslipidaemia risk (all lipid biomarkers beyond the risk threshold). The percentage of women categorized with atherogenic dyslipidaemia and inflammatory risk was lower in those with lower education level. Both lower-educated men and women had higher total dietary quality scores.

\section{Association of diet quality score with diabetes, atherogenic dyslipidaemia and inflammatory risk in men and women, overall and by education level} We did not find statistically significant associations of diet quality scores with diabetes, atherogenic dyslipidaemia or inflammatory risk in the overall sample of men and women (Fig. 1). Moreover, education level did not modify the association of dietary quality score with diabetes, atherogenic dyslipidaemia or inflammatory risk in men (Fig. 2). The education level in women modified the association between the diet quality score and diabetes risk $(P$-interaction $=0.04)$. For each increase of 10 units in the dietary quality score, the odds of diabetes risk in women with no reading/writing skills were about half $(\mathrm{OR}=0.47,95 \% \mathrm{CI} 0 \cdot 26,0.85)$ the odds of diabetes risk in women with $\geq 10$ years of school. The association between the total dietary quality score and atherogenic dyslipidaemia risk was also modified by education level ( $P$-interaction $<0 \cdot 01)$. For each 10 -unit increase in the dietary quality score, the odds of having one $v$. no lipid biomarker beyond the risk threshold in women with no reading/writing skills were 0.27 (95\% CI $0 \cdot 12,0.63)$ times the odds in women with higher education. Likewise, for each increase of 10 units in the dietary quality score, the odds of having all $v$. no lipid biomarker beyond the risk threshold in women with no reading/writing skills were 0.33 (95\% CI $0 \cdot 13,0.84$ ) times the odds in women with $\geq 10$ years of school. The association between total dietary quality score and inflammatory risk was not modified by education level.

\section{Results of sensitivity analyses}

Estimated odds of diabetes, atherogenic dyslipidaemia and inflammatory risk for each 10-unit increase in the total dietary quality score, in men and women, in the overall sample and by education level, were similar to those observed when we further adjusted models for physical activity (see online supplementary material, Supplemental Tables S2-S4). Likewise, estimations were similar to those observed when we did not consider corn tortillas as wholegrain cereals, but the interaction between the dietary quality score and education level in women for diabetes risk was no longer statistically significant (Supplemental Tables S5-S7).

\section{Discussion}

The current study is the first to analyse the cross-sectional association of diet quality with cardiometabolic risk in Mexican adults, to our knowledge. In the overall sample, diet quality was not associated with diabetes, atherogenic dyslipidaemia or inflammatory risk. The MxDQI may be a limited predictor of cardiometabolic risk in Mexican adults, a population undergoing the nutritional transition. Although the diet quality index was created to reflect current recommendations about dietary intake in Mexico, some food components and amounts of food components may not be the optimal for estimating diet quality as it relates to cardiometabolic disease risk in Mexican adults. For example, we did not categorize tortillas as cooked or fried, which could be relevant considering that both can be highly consumed in the Mexican population, but their associations with cardiometabolic risk will vary significantly based on cooking method. Additional modifications of this dietary index may be needed to reflect the cardiometabolic risk in this population. Moreover, the Mexican Dietary Guidelines, which we used as reference to develop the MxDQI, should be revised to assure they can prevent cardiometabolic diseases and other non-communicable diseases in the Mexican population.

We found that education level modified the association of dietary quality score with diabetes and atherogenic risk 
Table 2 Characteristics of Mexican men and women by education level, ENSANUT 2012 ( $n$ 1509)

\begin{tabular}{|c|c|c|c|c|c|c|c|c|c|c|c|c|}
\hline & \multicolumn{6}{|c|}{ Men } & \multicolumn{6}{|c|}{ Women } \\
\hline & \multicolumn{2}{|c|}{$\begin{array}{l}\text { No R/W } \\
\text { skills } \\
(n 75)\end{array}$} & \multicolumn{2}{|c|}{$\begin{array}{c}\mathrm{R} / \mathrm{W} \text { or } \\
3-9 \text { years } \\
\text { of school } \\
(n 422)\end{array}$} & \multicolumn{2}{|c|}{$\begin{array}{c}\geq 10 \text { years } \\
\text { of school } \\
(n 137)\end{array}$} & \multicolumn{2}{|c|}{$\begin{array}{c}\text { No R/W } \\
\text { skills } \\
(n \text { 92) }\end{array}$} & \multicolumn{2}{|c|}{$\begin{array}{c}\text { R/W skills } \\
\text { or 3-9 } \\
\text { years of } \\
\text { school } \\
(n 588)\end{array}$} & \multicolumn{2}{|c|}{$\begin{array}{c}\geq 10 \text { years } \\
\text { of school } \\
(n 195)\end{array}$} \\
\hline & $\begin{array}{l}\text { Mean } \\
\text { or } \%\end{array}$ & SE & $\begin{array}{l}\text { Mean } \\
\text { or } \%\end{array}$ & SE & $\begin{array}{l}\text { Mean } \\
\text { or } \%\end{array}$ & SE & $\begin{array}{l}\text { Mean } \\
\text { or } \%\end{array}$ & SE & $\begin{array}{l}\text { Mean } \\
\text { or } \%\end{array}$ & SE & $\begin{array}{l}\text { Mean } \\
\text { or } \%\end{array}$ & SE \\
\hline \multicolumn{13}{|l|}{ Sociodemographic } \\
\hline $\begin{array}{l}\text { Age (years), mean and SE } \\
\text { Area, \% and SE }\end{array}$ & 48 & $2 \cdot 3$ & 41 & $1 \cdot 0$ & 35 & $1 \cdot 6$ & 50 & $1 \cdot 7$ & 40 & $0 \cdot 7$ & 35 & $1 \cdot 1$ \\
\hline Urban & 46 & 7.5 & 66 & $3 \cdot 1$ & 82 & 3.7 & 54 & 7.9 & 70 & $2 \cdot 2$ & 79 & 3.6 \\
\hline Rural & 54 & $7 \cdot 5$ & 34 & $3 \cdot 1$ & 18 & $3 \cdot 7$ & 46 & $7 \cdot 9$ & 30 & $2 \cdot 2$ & 21 & 3.6 \\
\hline \multicolumn{13}{|l|}{ Region, \% and SE } \\
\hline North & 15 & $5 \cdot 1$ & 20 & $2 \cdot 3$ & 23 & $4 \cdot 2$ & 7 & $3 \cdot 1$ & 19 & 1.7 & 17 & $2 \cdot 6$ \\
\hline Central & 35 & $7 \cdot 4$ & 43 & $3 \cdot 7$ & 43 & $5 \cdot 8$ & 38 & $9 \cdot 2$ & 50 & $2 \cdot 6$ & 54 & 4.2 \\
\hline South & 51 & 7.5 & 37 & $3 \cdot 2$ & 34 & $5 \cdot 1$ & 55 & 8.7 & 31 & $2 \cdot 2$ & 29 & 3.6 \\
\hline \multicolumn{13}{|l|}{ Tertiles of assets index, $\%$ and SE } \\
\hline Low & 60 & $7 \cdot 9$ & 39 & $3 \cdot 1$ & 17 & 3.9 & 61 & 8.9 & 33 & $2 \cdot 7$ & 11 & 2.5 \\
\hline Medium & 26 & $7 \cdot 3$ & 32 & 3.4 & 32 & $5 \cdot 6$ & 21 & $6 \cdot 6$ & 34 & $2 \cdot 8$ & 22 & 3.7 \\
\hline High & 14 & $5 \cdot 8$ & 29 & $3 \cdot 7$ & 51 & $5 \cdot 8$ & 18 & $9 \cdot 2$ & 33 & $3 \cdot 2$ & 67 & 4.2 \\
\hline \multicolumn{13}{|l|}{ Health insurance/coverage, $\%$ and SE } \\
\hline Social & 21 & $6 \cdot 0$ & 26 & 3.4 & 44 & $5 \cdot 7$ & 34 & $9 \cdot 3$ & 32 & $2 \cdot 8$ & 51 & 4.8 \\
\hline Popular & 58 & 7.5 & 49 & 3.5 & 33 & $5 \cdot 7$ & 51 & 8.5 & 46 & $2 \cdot 9$ & 25 & $4 \cdot 1$ \\
\hline Uninsured & 21 & $6 \cdot 4$ & 25 & $2 \cdot 8$ & 23 & $4 \cdot 8$ & 15 & 4.9 & 23 & $2 \cdot 8$ & 24 & 3.9 \\
\hline \multicolumn{13}{|l|}{ Health } \\
\hline Glucose $(\mathrm{mg} / \mathrm{dl})$, mean and SE & 96 & 3.7 & 97 & 1.4 & 92 & $1 \cdot 2$ & 110 & $9 \cdot 3$ & 99 & 1.6 & 95 & 1.8 \\
\hline Diabetes risk (glucose $\geq 100 \mathrm{mg} / \mathrm{dl}$ ), $\%$ and SE & 29 & $6 \cdot 4$ & 25 & $3 \cdot 1$ & 17 & 3.7 & 36 & $8 \cdot 1$ & 33 & $2 \cdot 8$ & 25 & 4.2 \\
\hline TAG $(\mathrm{mg} / \mathrm{dl})$, mean and SE & 203 & $23 \cdot 4$ & 204 & $9 \cdot 0$ & 191 & $13 \cdot 2$ & 165 & $16 \cdot 1$ & 164 & $5 \cdot 4$ & 158 & 9.9 \\
\hline HDL-C (mg/dl), mean and SE & 38 & 1.3 & 37 & 0.6 & 36 & 0.8 & 41 & 1.0 & 41 & 0.6 & 42 & 0.8 \\
\hline LDL-C $(\mathrm{mg} / \mathrm{dl})$, mean and SE & 105 & $6 \cdot 3$ & 109 & $2 \cdot 4$ & 108 & $3 \cdot 3$ & 107 & 4.5 & 107 & $2 \cdot 4$ & 103 & $4 \cdot 1$ \\
\hline \multicolumn{13}{|l|}{$\begin{array}{l}\text { Atherogenic dyslipidaemia risk (number of lipid } \\
\text { biomarkers above the cut-off point), \% and SE }\end{array}$} \\
\hline None & 15 & 4.8 & 17 & $2 \cdot 6$ & 18 & 3.8 & 6 & 3.0 & 12 & $2 \cdot 1$ & 12 & 3.0 \\
\hline One & 32 & $7 \cdot 8$ & 29 & 3.4 & 27 & $5 \cdot 3$ & 48 & 8.4 & 38 & 2.9 & 44 & 4.9 \\
\hline Two & 34 & $7 \cdot 2$ & 42 & 3.4 & 43 & 5.9 & 40 & $8 \cdot 0$ & 38 & $3 \cdot 2$ & 31 & 4.6 \\
\hline Three & 19 & $5 \cdot \overline{1}$ & 12 & $2 \cdot 3$ & 12 & 3.7 & 6 & $2 \cdot 3$ & 11 & $1 . \overline{9}$ & 13 & 3.2 \\
\hline CRP (mg/l), mean and SE & 2 & 0.5 & 3 & 0.4 & 3 & 0.5 & 4 & 0.8 & 4 & 0.3 & 3 & 0.5 \\
\hline $\begin{array}{l}\text { Inflammatory risk (CRP > } 3 \mathrm{mg} / \mathrm{l} \text { but }<10 \mathrm{mg} / \mathrm{l}) \text {, } \\
\% \text { and SE }\end{array}$ & 14 & $3 \cdot 8$ & 16 & $2 \cdot 7$ & 23 & 5.5 & 22 & $5 \cdot 7$ & 30 & $2 \cdot 9$ & 27 & $4 \cdot 3$ \\
\hline \multicolumn{13}{|l|}{ Lifestyle } \\
\hline \multirow{2}{*}{\multicolumn{13}{|c|}{ Smoking status, $\%$ and SE }} \\
\hline & & & & & & & & & & & & \\
\hline Never & 53 & $7 \cdot 8$ & 47 & 3.4 & 59 & $5 \cdot 8$ & 97 & $2 \cdot 1$ & 85 & $2 \cdot 5$ & 74 & 4.4 \\
\hline Former & 24 & $6 \cdot 2$ & 29 & $3 \cdot 0$ & 20 & 4.3 & 0 & 0.0 & 12 & $2 \cdot 4$ & 13 & $3 \cdot 1$ \\
\hline Current & 24 & $6 \cdot 3$ & 24 & $3 \cdot 1$ & 21 & $5 \cdot 2$ & 3 & $2 \cdot 1$ & 4 & 1.0 & 13 & 3.7 \\
\hline \multicolumn{13}{|l|}{ Physical activity, $\%$ and SE } \\
\hline Inactive & 7 & $4 \cdot 0$ & 9 & $2 \cdot 2$ & 18 & 4.3 & 15 & 5.4 & 19 & 2.5 & 14 & $2 \cdot 8$ \\
\hline Moderately active & 15 & $6 \cdot 0$ & 10 & $2 \cdot 7$ & 11 & 3.7 & 10 & 5.9 & 13 & 1.9 & 7 & 2.5 \\
\hline Active & 78 & $6 \cdot 7$ & 81 & $3 \cdot 8$ & 70 & $5 \cdot 2$ & 75 & 7.4 & 69 & 2.9 & 79 & 3.6 \\
\hline \multicolumn{13}{|l|}{ Parity category, $\%$ and SE } \\
\hline None & - & - & - & - & - & - & 53 & 8.2 & 32 & $2 \cdot 9$ & 39 & $4 \cdot 8$ \\
\hline $1-2$ & - & - & - & - & - & - & 7 & $5 \cdot 7$ & 27 & 2.9 & 39 & 4.5 \\
\hline $3-4$ & - & - & - & - & - & - & 10 & $4 \cdot 0$ & 18 & $2 \cdot 2$ & 16 & 3.2 \\
\hline$\geq 5$ & - & - & - & - & - & - & 29 & 6.9 & 23 & $2 \cdot 2$ & 7 & $2 \cdot 2$ \\
\hline
\end{tabular}

ENSANUT, Mexican National Health and Nutrition Survey; R/W, reading/writing; HDL-C, HDL-cholesterol; LDL-C, LDL-cholesterol; CRP, C-reactive protein.

in women, but not men. For women with the lowest education level, a higher dietary quality score was associated with lower likelihood of diabetes and atherogenic dyslipidaemia risk in comparison to higher-educated women. The reasons underlying these findings are unclear. Some studies suggest that women with low education level have more psychosocial risks than men with the same level of education $^{(14,36)}$. Increased psychosocial risk may be associated with higher cardiometabolic risk in lower-educated women, as observed in previous studies ${ }^{(37)}$. Thus, one possibility is that a better diet quality may offset the higher likelihood of cardiometabolic risk by psychological factors only in lower-educated women. Another possibility is that the results observed in women can be due to chance, 
(a)

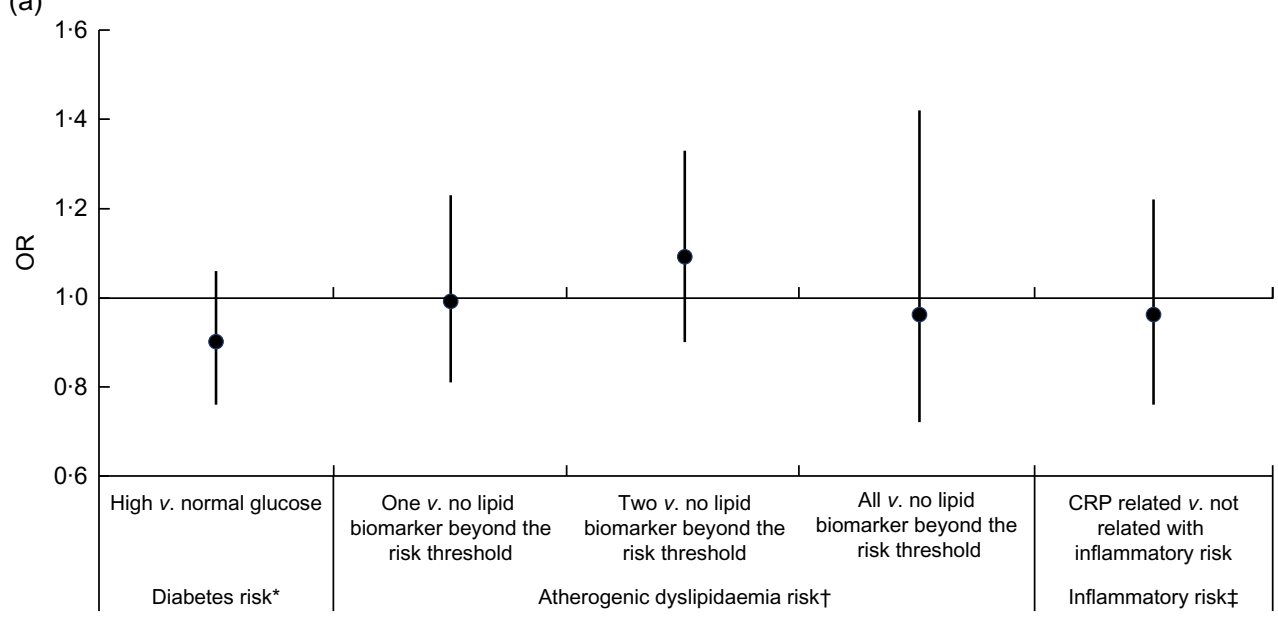

(b)

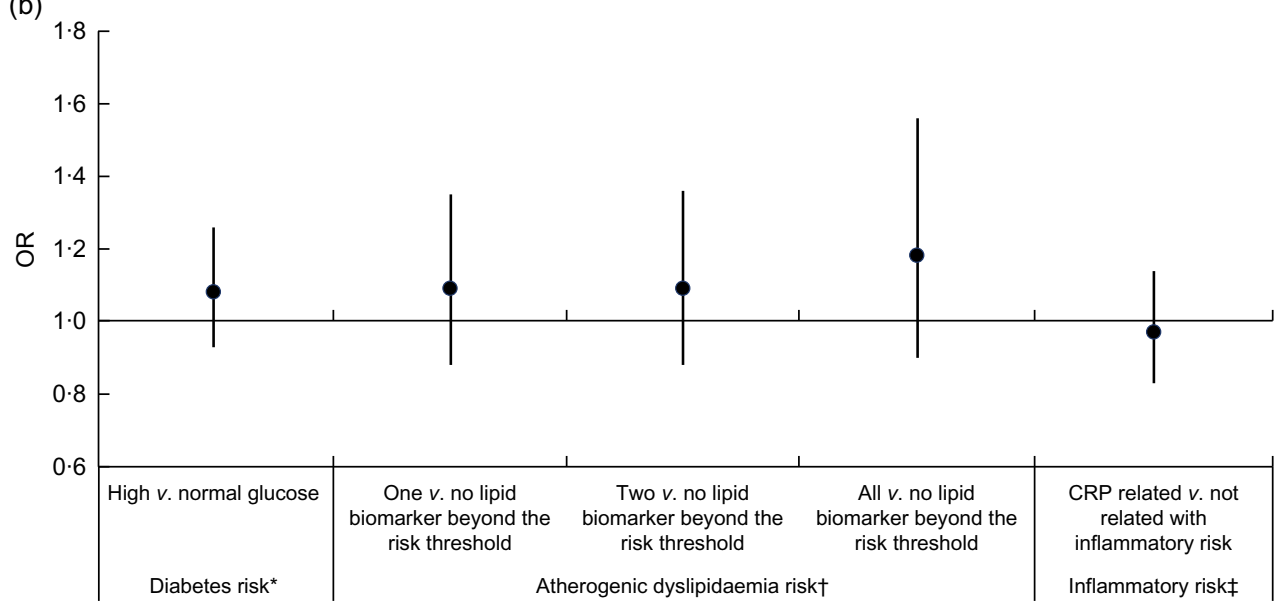

Fig. 1 Multivariable logistic regression models of the association between dietary quality score (10-unit increment) and cardiometabolic risks in Mexican men (a) and women (b), ENSANUT $2012(n$ 1509). Results are presented as OR (•) with their $95 \% \mathrm{Cl}$ represented by vertical bars. *High glucose: $\geq 100 \mathrm{mg} / \mathrm{dl}$. †Lipid biomarkers: high TAG ( $>150 \mathrm{mg} / \mathrm{dl})$, low HDL-cholesterol $(<40 \mathrm{mg} / \mathrm{dl}$ for men, $<50 \mathrm{mg} / \mathrm{dl}$ for women) and high LDL-cholesterol ( $>130 \mathrm{mg} / \mathrm{dll}$ ). $\ddagger$ CRP level related with inflammatory risk: $>3 \mathrm{mg} / \mathrm{l} \mathrm{but}<10 \mathrm{mg} / \mathrm{l}$ (ENSANUT, Mexican National Health and Nutrition Survey; CRP, C-reactive protein)

resulting from the multiple testing analyses. However, descriptive results indicate that the percentage of women categorized with diabetes and atherogenic dyslipidaemia risk as well as the total dietary score differed by education level. Therefore, education level may modify the association of diet quality with diabetes and atherogenic dyslipidaemia risk in women. Under the assumption that our results are not chance findings, future research focused on identifying mechanisms responsible for sex differences in the relationship between diet quality and cardiometabolic risk by education level would provide better knowledge of the potential pathways.

Several studies also indicate that low-educated women tend to have other risky lifestyle behaviours, such as smoking, low physical activity, sedentary activity or poor sleep duration ${ }^{(37-39)}$. High diet quality could counteract these factors and lead to reduced cardiometabolic risk. For higher-educated women, who have fewer other risk factors, a high-quality diet may not be sufficient to further reduce their cardiometabolic risk. It is unlikely smoking could influence the results observed in the present study since models were adjusted for this factor. Moreover, although we included physical activity as a covariate only in sensitivity analyses, results in women were similar to those observed in the main results. More research will be needed to understand whether other lifestyle factors, such as sleep duration and sedentary behaviours, modify the association between diet quality and cardiometabolic risk.

The observed inverse association of diet quality with risk of diabetes and atherogenic dyslipidaemia in lower$v$. higher-educated women may be also related to differential dietary misreporting. Dietary information was self-reported and therefore might be subject to social desirability ${ }^{(40)}$, which appears to bias more the dietary data of women than men ${ }^{(41,42)}$, and seems to be more common in higher-educated women ${ }^{(43,44)}$. If higher-educated women were more prone to social desirability in the present study, women who consumed more unhealthy 
(a)

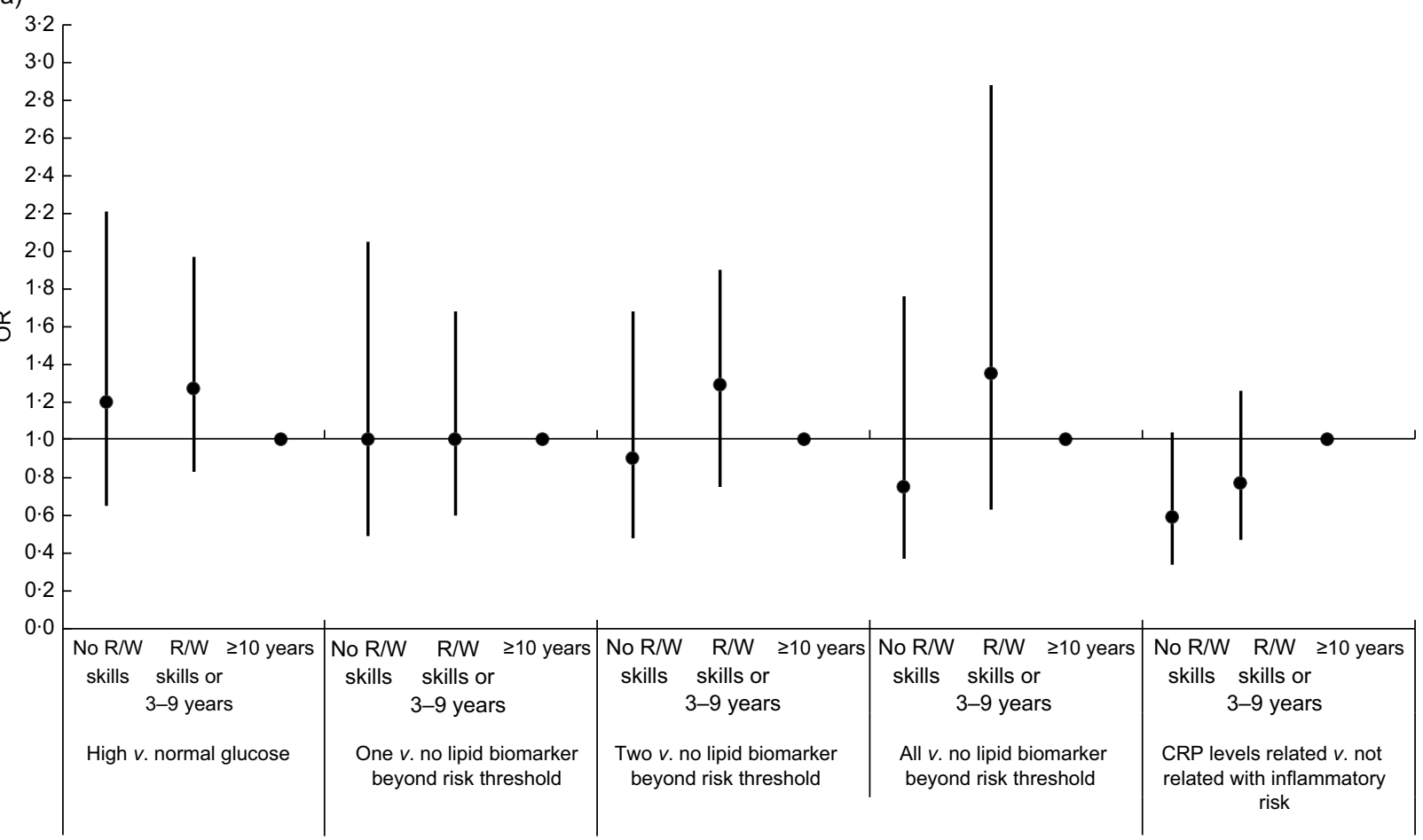

Diabetes risk*

Inflammatory risk $\ddagger$

(b)

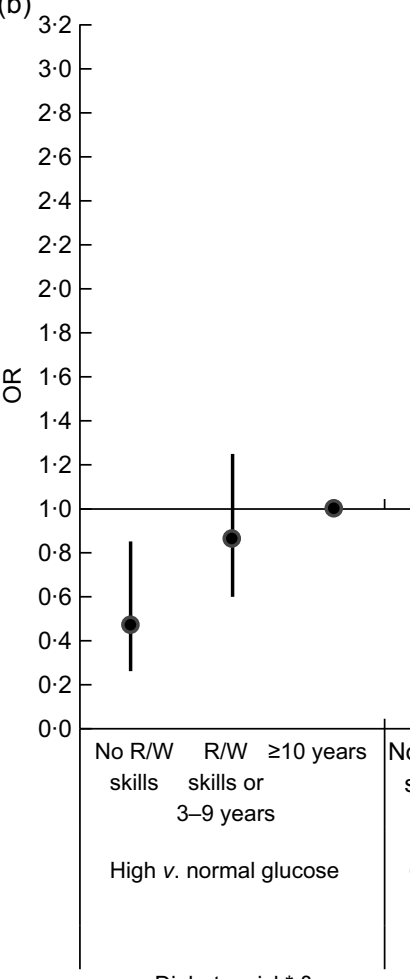

Diabetes risk* ${ }^{\star} \S$

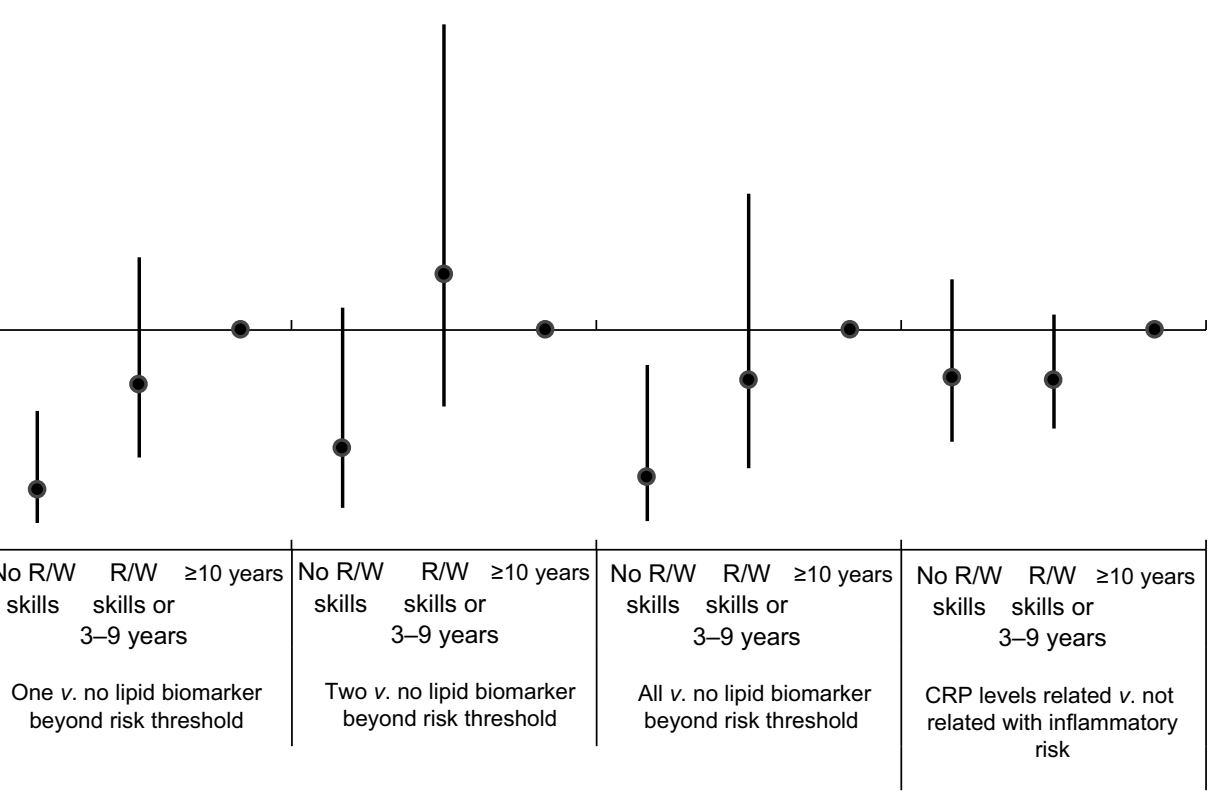

Atherogenic dyslipidaemia risk $†, \S$

Inflammatory risk‡

Fig. 2 Multivariable logistic regression models of the association between diet quality score (for each 10-unit increase) and cardiometabolic risks in Mexican men (a) and women (b) by education level, ENSANUT 2012 ( $n$ 1509). Results are presented as OR ( $\bullet$ ) with their $95 \% \mathrm{Cl}$ represented by vertical bars. *High glucose: $\geq 100 \mathrm{mg} / \mathrm{dl}$. †Lipid biomarkers: high TAG (>150 mg/dl), low HDLcholesterol ( $<40 \mathrm{mg} / \mathrm{dl}$ for men, $<50 \mathrm{mg} / \mathrm{dl}$ for women) and high LDL-cholesterol ( $>130 \mathrm{mg} / \mathrm{dl})$. $\ddagger$ CRP level related with inflammatory risk: $>3 \mathrm{mg} / \mathrm{l}$ but $<10 \mathrm{mg} / \mathrm{l}$. $\S P$-interaction < 0.05 (ENSANUT, Mexican National Health and Nutrition Survey; R/W, reading/writing; CRP, C-reactive protein) 
foods may not have reported them, making it look like their diet was more similar to women who consumed more healthy foods and thus obscuring the relationship between diet quality and CVD risk.

The interaction between dietary quality score and education level in women for diabetes risk was statistically significant when we classified corn tortillas as wholegrain cereals, but not when we did not consider it as such. These results suggest that corn tortillas not only contributed substantially to the wholegrain cereals, but also to the total diet quality score. Although it is uncertain whether all corn tortillas are made with whole grains, corn tortillas are characterized by low fat and low sodium content, and have $1.4 \mathrm{~g}$ of fibre for every $10 \mathrm{~g}$ of carbohydrates ${ }^{(45)}$, which might contribute to reduce the risk of diabetes. However, what is not clear from the current study is why we observed an association between the dietary quality score, considering tortillas as whole grain, and diabetes risk in lower-educated women only. Flores et $a l .{ }^{(46)}$ identified three major dietary patterns in Mexican adults in 2010. One of these patterns was traditional, where corn and corn-based foods accounted for almost $50 \%$ of energy intake and had the lowest contribution to total energy intake for most of the other food groups, except beans and legumes, compared with the other dietary patterns. Furthermore, the traditional pattern was associated with lower SES and higher fibre intake ${ }^{(46)}$. Other studies conducted in 2006 and 2014 found that Mexican adults with the lowest SES had the highest diet quality or traditional dietary pat$\operatorname{tern}^{(47,48)}$. Moreover, the expenditure on traditional foods, such as corn tortilla, is still higher in populations with lower income $^{(49)}$. It is possible that, in women with lower education, the consumption of corn tortillas reflects a healthier diet (with more traditional foods and less processed packaged foods or Western fast foods) which in turn could reduce the risk of diabetes, whereas higher-educated women who consume less corn tortillas (and a less healthier diet) are shifting more rapidly away from the traditional Mexican dietary pattern, increasing their risk of diabetes. Moreover, the findings about dietary patterns from previous investigations together with those observed in the present study could indicate that Mexican lower-educated women might be viewed as being in an early stage of the nutrition transition. However, other studies have also found that $\mathrm{BMI}^{(50)}$ and the prevalence of diabetes $^{(51)}$ are higher in lower-educated adults (including our study), which suggest this population truly fits more in the non-communicable disease stage (an advanced stage) of the nutrition transition ${ }^{(52)}$.

We observed that diet quality was not associated with diabetes, atherogenic dyslipidaemia or inflammatory risk in the overall sample of men, which may indicate that a better diet alone is not enough to reduce the risk of cardiometabolic diseases in men. Some studies indicate that physical activity and diet may have synergistic effects or that physical activity may be necessary to unmask the potential benefits of healthy diets on cardiometabolic risk ${ }^{(53,54)}$. A potential explanation of why the synergistic effects between diet and physical activity may be more likely in men than in women is that the former are more physically active. Unfortunately, we were unable to include physical activity in the main analyses due to the poor validity of the International Physical Activity Questionnaire short form in Mexican adults. Moreover, a larger sample size would be needed to assess the interaction between diet quality and physical activity. Future studies with larger sizes and more adequate measures of physical activity will be needed to evaluate whether physical activity modifies the association between diet quality and cardiometabolic risk in men.

Our analysis has several limitations that are important to acknowledge. First, it is not possible to establish a causal inference between diet quality and cardiometabolic risks given the cross-sectional nature of the study. Second, we estimated dietary quality scores based on a single $24 \mathrm{~h}$ recall, which may not represent the long-term dietary habits of the participants ${ }^{(55)}$. Third, the method we used to define atherogenic dyslipidaemia risk assumes that having lipid levels beyond the risk threshold in any of the lipid biomarkers has the same atherogenic risk. However, this classification is consistent with those used to analyse the risk of metabolic syndrome ${ }^{(23,56)}$. Last, we cannot rule out bias in the observed association between diet quality and atherogenic dyslipidaemia risk in women, since the sample of women with no reading/writing skills and normal levels in all lipid biomarkers was small $(n 7)$. Some simulation studies indicate that a minimum of 5-10 observations per variable in logistic regression models may be enough to obtain reliable results ${ }^{(57,58)}$. However, our results and interpretations need to be considered with caution until longitudinal studies with larger samples and detailed dietary data are conducted.

Despite the limitations, the current study highlights the potential modifying effect of education on the association between diet quality and cardiometabolic risk in women, but not men, using a representative sample of Mexican men and women, with detailed diet data as well as information on several key cardiometabolic biomarkers and covariates. These results suggest that lower-educated women may benefit most from interventions and policies that improve their diet quality. Future research will be needed to understand which approaches work best for increasing diet quality and preventing cardiometabolic risk among lower-educated Mexican women. In addition, for highereducated Mexican women and for Mexican men, for whom there was no relationship between diet quality and cardiometabolic disease risk, future research will be needed to identify what dietary and other factors will prevent cardiometabolic disease.

\section{Conclusion}

In conclusion, to the best of our knowledge, ours is the first study to assess the association between diet quality and 
cardiometabolic risk in Mexican adults, overall and by education level. There was no association between diet quality and cardiometabolic disease risk in Mexican adults. However, education level modified the association of diet quality with diabetes and atherogenic dyslipidaemia risk in Mexican women, but not in men. A higher diet quality was associated with lower diabetes and atherogenic dyslipidaemia risk in lower- but not higher-educated women. Our findings suggest that Mexican women with low SES could be targeted for interventions focused on improving the quality of their diet and, in turn, reduce the likelihood of diabetes and atherogenic dyslipidaemia risk. More research using larger sample sizes and longitudinal data is needed to confirm and add evidence or insights about the nature of these associations.

\section{Acknowledgements}

Acknowledgements: The authors thank Dr Phil Bardsley for exceptional assistance with the data management, Ms Emily Ford Yoon and Ms Frances Dancy Burton for administrative assistance, and Ms Denise Ammons for graphics support. Financial support: This work was funded primarily by Bloomberg Philanthropies (grants to the University of North Carolina and the Center for Nutrition and Health Research, National Institute of Public Health of Mexico), with support from the National Institutes of Health $\mathrm{NIH}$; grant number R01DK108148) and the Carolina Population Center and its NIH Center grant (grant number P2C HD050924). N.L.-O. is supported by a Mexican National Council for Science and Technology (CONACyT) scholarship. Funders had no role in the design, analysis or writing of this article. Conflict of interest: None. Authorship: N.L.-O., B.M.P. and L.S.T. were responsible for study design, results interpretation and writing the manuscript. N.L.-O. was responsible for performing statistical analyses and drafting and editing of the manuscript. All authors contributed to study design and critical revision of the manuscript. All authors approved the final manuscript. Ethics of buman subject participation: This study was conducted according to the guidelines laid down in the Declaration of Helsinki and all procedures involving human subjects were approved by the Ethics Committee of the Mexican National Institute of Public Health. Written informed consent was obtained from all subjects under study.

\section{Supplementary material}

To view supplementary material for this article, please visit https://doi.org/10.1017/S1368980019001678

\section{References}

1. Gómez-Dantés H, Fullman N, Lamadrid-Figueroa $\mathrm{H}$ et al. (2016) Dissonant health transition in the states of Mexico, 1990-2013: a systematic analysis for the Global Burden of Disease Study 2013. Lancet 388, 2386-2402.
2. Arvaniti F \& Panagiotakos DB (2008) Healthy indexes in public health practice and research: a review. Crit Rev Food Sci Nutr 48, 317-327.

3. Harmon BE, Boushey CJ, Shvetsov YB et al. (2015) Associations of key diet-quality indexes with mortality in the Multiethnic Cohort: the Dietary Patterns Methods Project. Am J Clin Nutr 101, 587-597.

4. Schwingshackl L \& Hoffmann G (2015) Diet quality as assessed by the Healthy Eating Index, the Alternate Healthy Eating Index, the Dietary Approaches to Stop Hypertension score, and health outcomes: a systematic review and meta-analysis of cohort studies. J Acad Nutr Diet 115, 780-800.e5.

5. Wang Z, Adair LS, Cai J et al. (2017) Diet quality is linked to insulin resistance among adults in China. J Nutr 147, 21022108.

6. Siervo M, Lara J, Chowdhury S et al. (2015) Effects of the Dietary Approach to Stop Hypertension (DASH) diet on cardiovascular risk factors: a systematic review and metaanalysis. Br J Nutr 113, 1-15.

7. Estruch R, Ros E, Salas-Salvado J et al. (2013) Primary prevention of cardiovascular disease with a Mediterranean diet. $N$ Engl J Med 368, 1279-1290.

8. Shirani F, Salehi-Abargouei A \& Azadbakht L (2013) Effects of Dietary Approaches to Stop Hypertension (DASH) diet on some risk for developing type 2 diabetes: a systematic review and meta-analysis on controlled clinical trials. Nutrition $\mathbf{2 9}$, 939-947.

9. Neale E, Batterham M \& Tapsell LC (2016) Consumption of a healthy dietary pattern results in significant reductions in Creactive protein levels in adults: a meta-analysis. Nutr Res 36, 391-401.

10. AlEssa HB, Malik VS, Yuan C et al. (2016) Dietary patterns and cardiometabolic and endocrine plasma biomarkers in US women, 2. Am J Clin Nutr 105, 432-441.

11. Hafiane A \& Genest J (2015) High density lipoproteins: measurement techniques and potential biomarkers of cardiovascular risk. BBA Clin 3, 175-188.

12. Aleksandrova K, Mozaffarian D \& Pischon T (2018) Addressing the perfect storm: biomarkers in obesity and pathophysiology of cardiometabolic risk. Clin Chem 64, 142-153.

13. Abbasalizad Farhangi M, Ataie-Jafari A, Najafi M et al. (2016) Gender differences in major dietary patterns and their relationship with cardio-metabolic risk factors in a year before coronary artery bypass grafting (CABG) surgery period. Arch Iran Med 19, 470-479.

14. Kavanagh A, Bentley RJ, Turrell G et al. (2010) Socioeconomic position, gender, health behaviours and biomarkers of cardiovascular disease and diabetes. Social Sci Med 71, 1150-1160.

15. López-Olmedo N, Carriquiry AL, Rodríguez-Ramírez S et al. (2016) Usual intake of added sugars and saturated fats is high while dietary fiber is low in the Mexican population. J Nutr 146, issue 9, 1856S-1865S.

16. Aburto TC, Pedraza LS, Sanchez-Pimienta TG et al. (2016) Discretionary foods have a high contribution and fruit, vegetables, and legumes have a low contribution to the total energy intake of the Mexican population. J Nutr 146, issue 9, 1881S-1887S.

17. Flores M, Macias N, Rivera M et al. (2009) Energy and nutrient intake among Mexican school-aged children, Mexican National Health and Nutrition Survey 2006. Salud Publica Mex 51, Suppl. 4, S540-S550.

18. Howe LD, Galobardes B, Matijasevich A et al. (2012) Measuring socio-economic position for epidemiological studies in low-and middle-income countries: a methods of measurement in epidemiology paper. Int J Epidemiol 41, 871-886.

19. Liberatos P, Link BG \& Kelsey JL (1988) The measurement of social class in epidemiology. Epidemiol Rev 10, 87-121. 
20. Lynch JL \& von Hippel PT (2016) An education gradient in health, a health gradient in education, or a confounded gradient in both? Soc Sci Med 154, 18-27.

21. Zajacova A \& Lawrence EM (2018) The relationship between education and health: reducing disparities through a contextual approach. Annu Rev Public Health 39, 273-289.

22. Friedewald WT, Levy RI \& Fredrickson DS (1972) Estimation of the concentration of low-density lipoprotein cholesterol in plasma, without use of the preparative ultracentrifuge. Clin Chem 18, 499-502.

23. International Diabetes Federation (2006) The IDF Consensus Worldwide Definition of Metabolic Syndrome. Brussels: IDF.

24. Expert Panel on Detection, Evaluation, and Treatment of High Blood Cholesterol in Adults (2001) Executive summary of the Third Report of the National Cholesterol Education Program (NCEP) Expert Panel on Detection, Evaluation, and Treatment of High Blood Cholesterol in Adults (Adult Treatment Panel III). JAMA 285, 2486-2497.

25. Pearson TA, Mensah GA, Alexander RW et al. (2003) Markers of inflammation and cardiovascular disease: application to clinical and public health practice: a statement for healthcare professionals from the Centers for Disease Control and Prevention and the American Heart Association. Circulation 107, 499-511.

26. Blanton CA, Moshfegh AJ, Baer DJ et al. (2006) The USDA Automated Multiple-Pass Method accurately estimates group total energy and nutrient intake. J Nutr 136, 2594-2599.

27. Conway JM, Ingwersen LA, Vinyard BT et al. (2003) Effectiveness of the US Department of Agriculture 5-step multiple-pass method in assessing food intake in obese and nonobese women. Am J Clin Nutr 77, 1171-1178.

28. Bonvecchio-Arenas A, Fernández-Gaxiola AC, PlazasBelusteguigoitia M et al. (2015) Guías Alimentarias y de Actividad Física en Contexto de Sobrepeso y Obesidad en la Población Mexicana (Dietary and Physical Activity Guidelines in the Context of Overweight and Obesity in the Mexican Population). Ciudad de México: Academia Nacional de Medicina.

29. Rivera JA, Muñoz-Hernández O, Rosas-Peralta M et al. (2008) Consumo de bebidas para una vida saludable: recomendaciones para la población mexicana. Salud Publica Mex 50, 173-195.

30. Bourges H, Casanueva E \& Rosado J (2008) Recomendaciones de Ingestion de Nutrimentos para la Poblacion Mexicana: Bases Fiosiológicas (Recommendations of Nutrient Intake for the Mexican Population: Physiological Basis). Mexico City: Editorial Médica Panamericana.

31. World Health Organization (2015) Guideline: Sugars Intake for Adults and Children. Geneva: WHO.

32. World Health Organization/Food and Agriculture Organization of the United Nations (2003) Diet, Nutrition and Prevention of Chronic Diseases. Report of a Joint WHO/FAO Expert Consultation. WHO Technical Report Series no. 916. Geneva: WHO.

33. Sánchez-Pimienta TG, Batis C, Lutter CK et al. (2016) Sugarsweetened beverages are the main sources of added sugar intake in the Mexican population. J Nutr 146, issue 9, 1888S-1896S.

34. Vallejo M, Colin-Ramirez E, Rivera Mancia S et al. (2017) Assessment of sodium and potassium intake by $24 \mathrm{~h}$ urinary excretion in a healthy Mexican cohort. Arch Med Res 48, 195-202.

35. Medina C, Barquera S \& Janssen I (2013) Validity and reliability of the International Physical Activity Questionnaire among adults in Mexico. Rev Panam Salud Publica 34, 21-28.

36. Loucks EB, Rehkopf DH, Thurston RC et al. (2007) Socioeconomic disparities in metabolic syndrome differ by gender: evidence from NHANES III. Ann Epidemiol 17, 19-26.

37. McCurley JL, Penedo F, Roesch SC et al. (2017) Psychosocial factors in the relationship between socioeconomic status and cardiometabolic risk: the HCHS/SOL Sociocultural Ancillary Study. Ann Behav Med 51, 477-488.

38. Cutler DM \& Lleras-Muney A (2010) Understanding differences in health behaviors by education. $J$ Health Econ 29, 1-28.

39. Staiano A, Harrington D, Barreira T et al. (2014) Sitting time and cardiometabolic risk in US adults: associations by sex, race, socioeconomic status and activity level. $\mathrm{Br} J$ Sports Med 48, 213-219.

40. Kipnis V, Midthune D, Freedman L et al. (2002) Bias in dietary-report instruments and its implications for nutritional epidemiology. Public Health Nutr 5, 915-923.

41. Hebert JR, Ma Y, Clemow L et al. (1997) Gender differences in social desirability and social approval bias in dietary selfreport. Am J Epidemiol 146, 1046-1055.

42. Novotny JA, Rumpler WV, Riddick H et al. (2003) Personality characteristics as predictors of underreporting of energy intake on 24-hour dietary recall interviews. J Acad Nutr Diet 103, 1146-1151.

43. Hébert JR, Peterson KE, Hurley TG et al. (2001) The effect of social desirability trait on self-reported dietary measures among multi-ethnic female health center employees. Ann Epidemiol 11, 417-427.

44. Bothwell EK, Ayala GX, Conway TL et al. (2009) Underreporting of food intake among Mexican/MexicanAmerican women: rates and correlates. J Acad Nutr Diet 109, 624-632.

45. US Department of Agriculture, Agricultural Research Service, Nutrient Data Laboratory (2013) National Nutrient Database for Standard Reference, Release 24. https://www.ars.usda. gov/northeast-area/beltsville-md/beltsville-human-nutritionresearch-center/nutrient-data-laboratory/docs/sr24-home-page/ (accessed January 2017).

46. Flores M, Macias N, Rivera M et al. (2010) Dietary patterns in Mexican adults are associated with risk of being overweight or obese. J Nutr 140, 1869-1873.

47. Bojorquez I, Unikel C, Cortez I et al. (2015) The social distribution of dietary patterns. Traditional, modern and healthy eating among women in a Latin American city. Appetite 92, 43-50.

48. Ponce X, Rodriguez-Ramirez S, Mundo-Rosas V et al. (2014) Dietary quality indices vary with sociodemographic variables and anthropometric status among Mexican adults: a crosssectional study. Results from the 2006 National Health and Nutrition Survey. Public Health Nutr 17, 1717-1728.

49. Moreno-Altamirano L, Capraro S, Panico C et al. Estructura económica, distribución del ingreso, patrones de alimentación y las condiciones nutricionales en México (Economic structure, distribution of income, dietary patterns and nutritional conditions in Mexico). Economía UNAM 15 , 29-49.

50. Basto-Abreu A, Barrientos-Gutierrez T, Zepeda-Tello R et al. (2018) The relationship of socioeconomic status with body mass index depends on the socioeconomic measure used. Obesity (Silver Spring) 26, 176-184.

51. Rojas-Martinez R, Basto-Abreu A, Aguilar-Salinas CA et al. (2018) Prevalence of previously diagnosed diabetes mellitus in Mexico. Salud Publica Mex 60, 224-232.

52. Popkin BM (2002) The shift in stages of the nutrition transition in the developing world differs from past experiences! Public Health Nutr 5, 205-214.

53. Muldoon MF, Erickson KI, Goodpaster BH et al. (2013) Concurrent physical activity modifies the association between $\mathrm{n} 3$ long-chain fatty acids and cardiometabolic risk in midlife adults. J Nutr 143, 1414-1420. 
54. Elliot CA \& Hamlin MJ (2018) Combined diet and physical activity is better than diet or physical activity alone at improving health outcomes for patients in New Zealand's primary care intervention. BMC Public Health 18, 230.

55. Dodd KW, Guenther PM, Freedman LS et al. (2006) Statistical methods for estimating usual intake of nutrients and foods: a review of the theory. J Am Diet Assoc 106, 1640-1650.

56. Alberti KG, Zimmet P \& Shaw J (2006) Metabolic syndrome a new world-wide definition. A Consensus Statement from the International Diabetes Federation. Diabet Med 23, 469-480.

57. Concato J, Peduzzi P, Holford TR et al. (1995) Importance of events per independent variable in proportional hazards analysis I. Background, goals, and general strategy. J Clin Epidemiol 48, 1495-1501.

58. Peduzzi P, Concato J, Kemper E et al. (1996) A simulation study of the number of events per variable in logistic regression analysis. J Clin Epidemiol 49, 1373-1379. 